\title{
On Writing Abstracts
}

When Nicholas Nickleby was ordered by Mr. Vincent Crummles to write a play, the only condition was that he should introduce a real pump and two washing tubs. "That's the London plan" said Mr. Crummles. "They look up some dresses and properties, and have a piece written to fit 'em."

In the conduction of such a journal as the BRITISH JoURNAL OF OPHTHALMOLOGY the editors have to depend upon the pump and washing tubs supplied by those willing helpers who write abstracts, and month by month, to pick out a certain number of headings and group under these the abstracts that are in hand. This was the "London plan" adopted by the Ophthalmoscope and the practice has been continued in this journal. No attempt is made to give a complete review of current literature; for such a purpose the Jahresbericht and the Ophthalmic Year Book are sufficient.

In writing an abstract it should be remembered that what is wanted is a description of the author's paper sufficient to enable a reader of our journal to get at the facts. Criticism of the author's statements as a rule is not wanted; this can usually be supplied by the reader himself; it is quite different from the review of a book, where criticism is not only desirable but welcome. If a book is unorthodox or manifestly wrong in the statements which it contains, it is perfectly right for the reviewer to call attention to such mistakes.

No journal in the world, so far as we are aware, holds itself responsible for the mistakes of its authors, and if a paper is submitted which is obviously unsuited for publication, it is refused. If a paper is not worth abstracting, it is best not to attempt it ; if it so diffuse as to make its condensation a matter of impossibility, the same plan should be adopted.

The management of this publication are endeavouring to organize the abstracts so as to increase the value of this section of the journal ; those of our readers who are willing to help in this matter are asked to send their names and a note of the subjects in which they are specially interested to the Secretary of the Committee of Abstracts, Mr. F. A. Williamson-Noble, 27, Harley Street, W.1. 